\title{
INCLUSÃO E EXCLUSÃO DIGITAL EM CONTEXTOS DE PANDEMIA: QUE EDUCAÇÃO ESTAMOS PRATICANDO E PARA QUEM?
}

Karina Marcon ${ }^{1}$

\begin{abstract}
Resumo: Em um contexto de pandemia, no Brasil e no mundo, as tecnologias digitais de rede foram sendo adotadas na mediação de processos de ensino-aprendizagem, seja na educação básica ou na educação superior. No cenário brasileiro, dados da Pesquisa TIC Domicílios 2019 (CGI.br, 2019) denunciam que apenas 39\% dos domicílios brasileiros possuem computador e que $28 \%$ dos domicílios não possuem acesso à internet. Para além do acesso, estudos sobre inclusão digital reforçam a necessidade de se pensar na apropriação social das tecnologias, implicando não somente na instrumentalização e na fluência tecnológica, mas na apropriação crítica, autoral e criativa das tecnologias digitais e no exercício da cidadania na rede. Neste sentido, o que significa ser um excluído digital em um contexto de isolamento social? Que educação estamos praticando e para quem, neste contexto de pandemia?
\end{abstract}

Palavras-chave: Inclusão Digital; Exclusão Digital; Formação de Professores; Pandemia.

\section{DIGITAL INCLUSION AND EXCLUSION IN PANDEMIC CONTEXTS: WHAT EDUCATION ARE WE PRACTICING AND FOR WHOM?}

\begin{abstract}
In a pandemic context, in Brazil and in the world, digital network technologies were been adopted in the mediation of teaching-learning processes, either in basic education or in higher education. In the Brazilian scenario, data from the 2019 ICT Household Survey (CGI.br, 2019) show that only $39 \%$ of Brazilian households have a computer and that $28 \%$ of households do not have access to the internet. In addition to access, studies on digital inclusion reinforce the need to think about the social appropriation of technologies, implying not only the instrumentalization and technological fluency, but the critical, authorial and creative appropriation of digital technologies and the exercise of citizenship in the network. In this sense, what does it mean to be a digitally excluded in a context of social isolation? What education are we practicing and for whom, in this pandemic context?
\end{abstract}

Keywords: Digital Inclusion; Digital Exclusion; Teacher Training; Pandemic.

\footnotetext{
${ }^{1}$ Doutora em Educação (UFRGS). Professora Efetiva na Universidade do Estado de Santa Catarina (UDESC). Endereço postal: Rodovia Amaro Antônio Vieira, 2463 apto 203 bloco A. Bairro Itacorubi. CEP: 88034-102. Florianópolis/SC. Endereço eletrônico: karina.marcon@udesc.br
} 


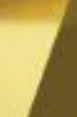
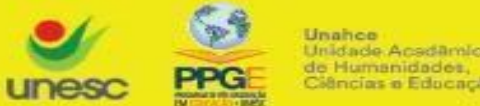 \\ unesc PPG \\ ediunese}

Criar Educação, Criciúma, v. 9, n²2, Edição Especial 2020.- PPGE - UNESC - ISSN 2317-2452

\section{Introdução}

A pandemia da Covid 19 transformou nossas vidas, e de um momento para outro tivemos que nos adaptar a uma nova realidade e passamos a viver em um contexto de isolamento social, situação que alterou nossa rotina de estudos, trabalho, esporte e lazer.

No campo da educação, no Brasil e no mundo, as tecnologias digitais de rede (TDR) foram sendo adotadas na mediação de processos de ensino-aprendizagem durante a pandemia, seja na educação básica ou na educação superior. Nesse contexto, torna-se urgente debater sobre inclusão digital, principalmente na medida em que constatamos que ainda existe uma parcela da população que se encontra excluída e que não tem acesso a computadores e internet. Direcionamos nosso olhar principalmente a essa nova dinâmica que surge com a pandemia e a urgência de se apropriar das tecnologias digitais de rede para efetivação dos processos de ensino-aprendizagem.

Diante desse contexto, pensamos que movimentos de inclusão digital, entendidos como mais do que o acesso, implicam uma apropriação social das tecnologias digitais de rede (MARCON, 2008). O potencial criativo e comunicacional dessas tecnologias fomenta o desenvolvimento de habilidades inerentes a uma cultura de rede, como a participação, o compartilhamento, a autonomia, a autoria, a interatividade, a coletividade e a cooperação.

Admitida a importância da inclusão digital no cenário educativo contemporâneo, pensamos ser urgente refletir sobre a formação de professores, para que possam reconhecer e participar dessas novas dinâmicas instituídas. Acreditamos que o professor é um ator central e precisa estar preparado para operar nesse novo cenário social.

$\mathrm{Na}$ realidade da sociedade brasileira, observamos que as tecnologias estão sendo adotadas de forma acelerada na mediação dos processos educativos, com formação técnica e não pedagógica, excluindo uma parcela significativa de estudantes que não tem acesso. Neste contexto, parece ser urgente refletir sobre o conceito de inclusão digital na atualidade e sobre o que significa, de fato, ser um excluído digital em um contexto de isolamento social. 


\section{CRIAR EDUCAÇÃO}

Revista do Programa de Pós-Graduação em Educação - UNESC

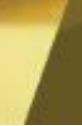
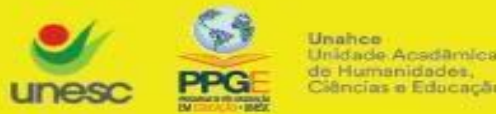 \\ ediunese}

Criar Educação, Criciúma, v. 9, n²2, Edição Especial 2020.- PPGE - UNESC - ISSN 2317-2452

Nos propomos a discutir também, neste texto, o potencial pedagógico das tecnologias digitais de rede para os processos educativos, as implicações da inclusão e da exclusão digital na formação de educadores e seus desdobramentos nas práticas pedagógicas.

\section{Para além do acesso: o que é inclusão digital?}

Para falar sobre processos de inclusão digital precisamos, em um primeiro momento, discorrer sobre os dados referentes ao acesso da população à internet. No cenário brasileiro, dados recentes da Pesquisa TIC Domicílios 2019 (CGI.br, 2019) denunciam que apenas 39\% dos domicílios brasileiros possuem computador e que há uma grande diferença por classe social, atingindo somente $14 \%$ das classes DE.

\section{Imagem 01 - Domicílios com computador no Brasil}

Domicílios com computador

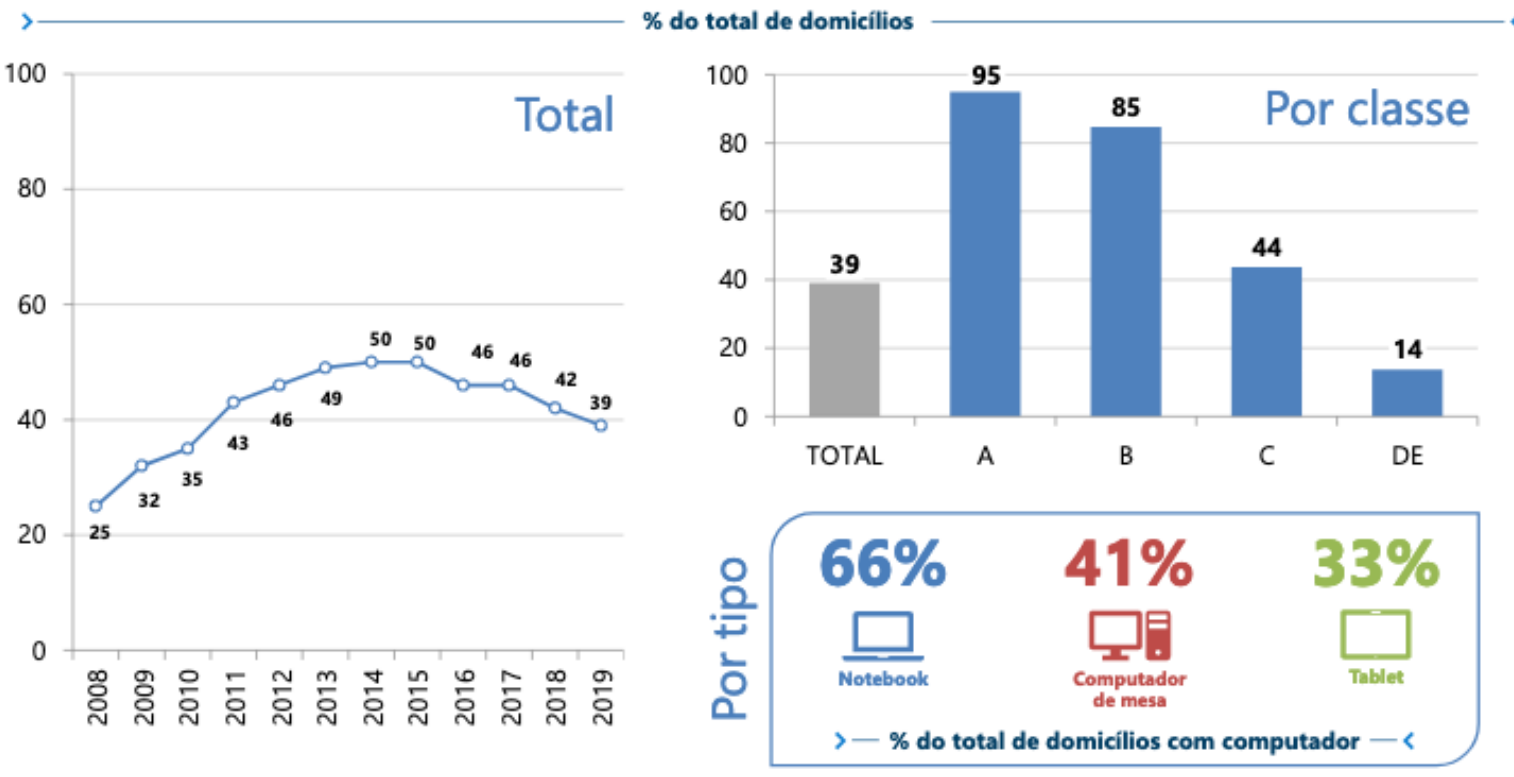

Fonte: TIC Domicílios 2019 (CGI.br, 2018)

A disparidade de acesso por classe é visível e, portanto, a primeira conclusão que chegamos é de que em um contexto de isolamento social, as pessoas não possuem as mesmas condições de acesso aos computadores em seus domicílios. 


\section{CRIAR EDUCAÇÃO}

Revista do Programa de Pós-Graduação em Educação - UNESC

\section{(1)

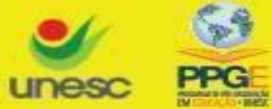

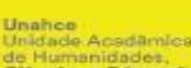 \\ CSancias a Educaçsic \\ ediunese}

Criar Educação, Criciúma, v. 9, №2, Edição Especial 2020.- PPGE - UNESC - ISSN 2317-2452

O gráfico abaixo apresenta o total de usuários de internet no ano de 2019, especificando também por classe social:

Imagem 02 - Usuários de internet no Brasil: total e classe social

Domicílios com acesso à Internet

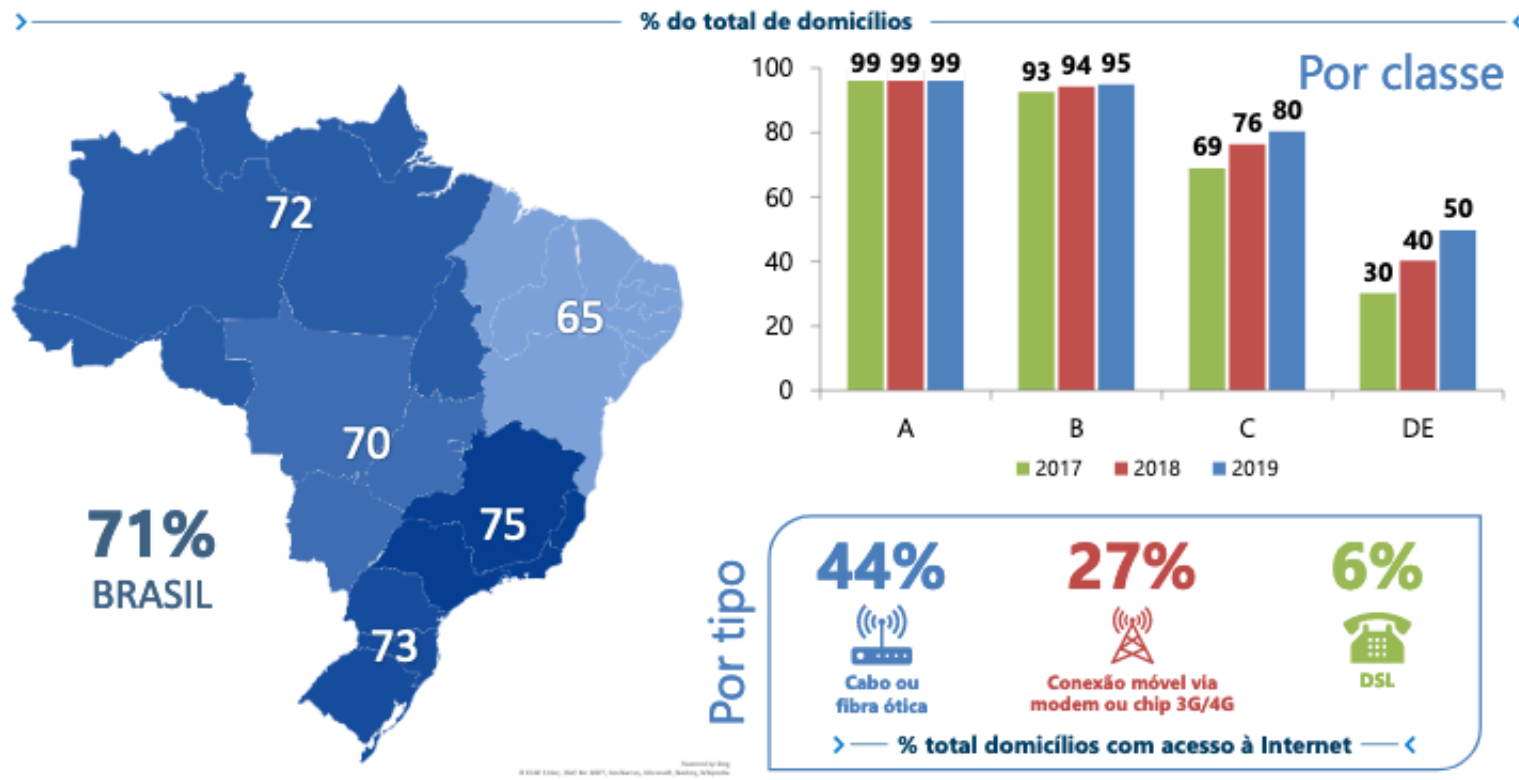

Fonte: TIC Domicílios 2019 (CGI.br, 2019)

Podemos perceber que $71 \%$ dos brasileiros utilizaram a internet no ano de 2019, sendo 99\%, 95\% e $80 \%$ das classes A, B e C, respectivamente, e $50 \%$ das classes DE. Apesar de observarmos no gráfico uma curva de crescimento de $10 \%$ referente ao ano anterior (2018), a população das classes DE é a que menos utilizou a internet, com pouco mais da metade dos acessos feitos pelas classes sociais mais altas. Esses dados apontam que as condições de acesso referem-se, também, ao poder aquisitivo das pessoas, sendo que a vulnerabilidade econômica da população influencia e restringe o acesso à internet. De acordo com a CGI.br, um a cada quatro brasileiros não usa a internet (47 milhões de não usuários), chegando a $26 \%$ da população. 


\section{CRIAR EDUCAÇÃO}

Revista do Programa de Pós-Graduação em Educação - UNESC

\section{unesc PPGE}

Criar Educação, Criciúma, v. 9, n²2, Edição Especial 2020.- PPGE - UNESC - ISSN 2317-2452

Desse universo de $71 \%$ que utilizaram a internet, $99 \%$ fez uso por meio do telefone celular, $42 \%$ microcomputador, $37 \%$ televisão e $9 \%$ aparelho de videogame, conforme podemos observar no gráfico que segue:

Imagem 03 - Dispositivos utilizados para acesso individual à internet

Usuários de Internet, por dispositivo utilizado - 2014-2019

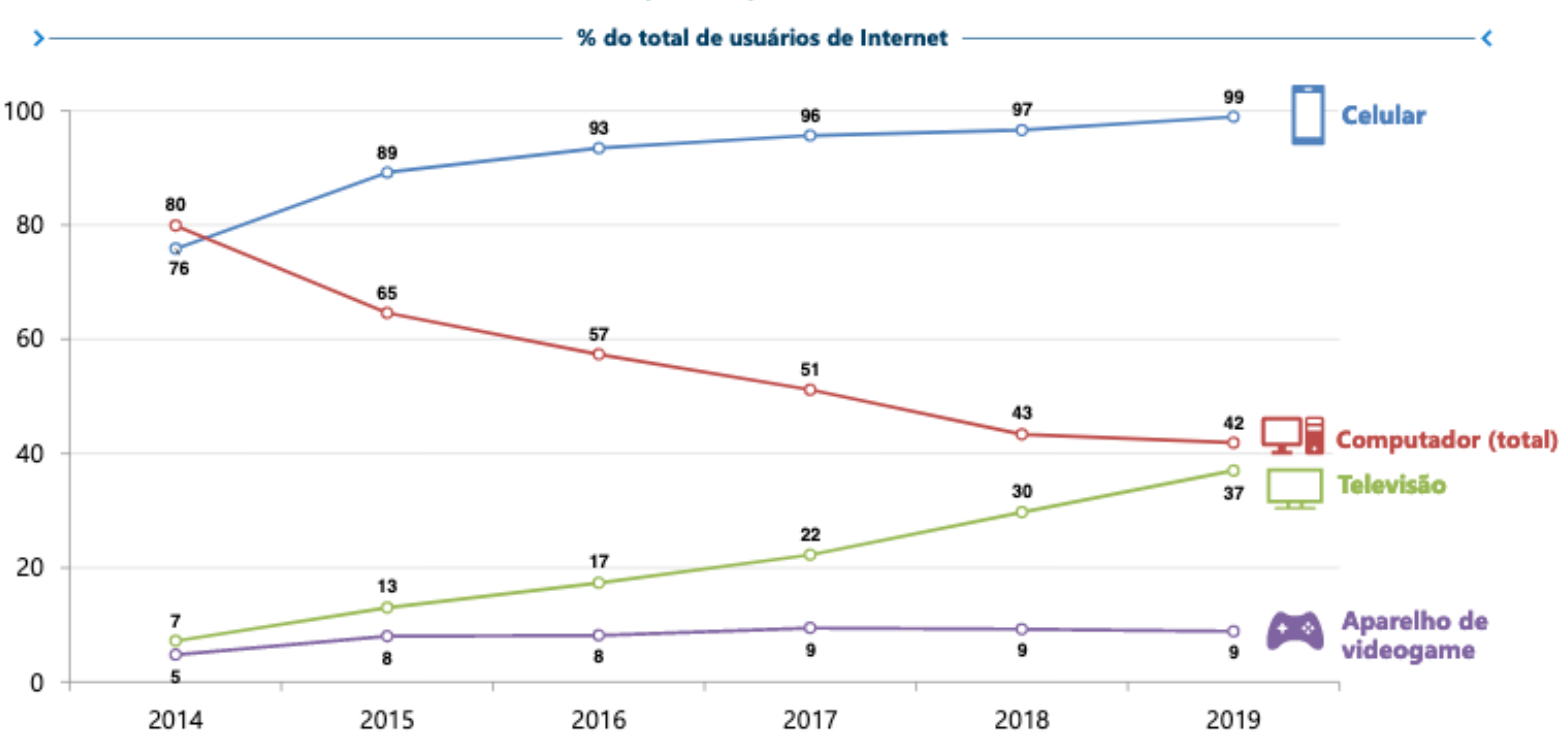

Fonte: TIC Domicílios 2019 (CGI.br, 2019)

É possível identificar que a maioria das pessoas utiliza internet por meio da telefonia móvel, com um percentual de $57 \%$ de diferença com a população que acessou via computador. Esse dado é significativo, principalmente em um contexto de pandemia e isolamento social, no qual as tecnologias digitais de rede vêm sendo adotadas na mediação de processos de ensino-aprendizagem, seja na educação básica ou na educação superior. Será que os processos de ensino-aprendizagem estão sendo pensados em um contexto no qual o educando só tenha acesso à internet via telefone celular, por exemplo? 


\title{
CRIAR EDUCAÇÃO
}

Revista do Programa de Pós-Graduação em Educação - UNESC

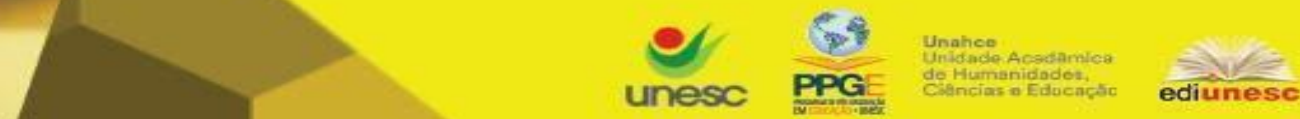

Criar Educação, Criciúma, v. 9, n²2, Edição Especial 2020.- PPGE - UNESC - ISSN 2317-2452

Para além do acesso, ainda há que considerar que processos de inclusão digital precisam suplantar a concepção simplista de acesso e de instrumentalização às tecnologias. Bonilla $(2004$, p. 01$)$ assinala a necessidade de se repensar os processos de apropriação tecnológica:

\begin{abstract}
Romper com essa perspectiva implica extrapolar o reducionismo feito ao conceito de inclusão digital e abordá-lo na perspectiva da participação ativa, da produção de cultura e conhecimento, o que implica políticas públicas que invistam efetivamente na capacitação dos professores, oportunizando-lhes condições para questionar, produzir, decidir, transformar, participar da dinâmica social em todas as suas instâncias, bem como trabalhar com seus alunos nessa perspectiva.
\end{abstract}

Para a autora, é necessário que se supere a visão trivial de inclusão digital como mera utilização das tecnologias. Inclusão digital requer a participação do sujeito na rede e o posicionamento como ser produtor de cultura e de conhecimento. Para Lemos (2011, p. 19),

[...] mais do que dar acesso às tecnologias (uma condição técnica imprescindível e básica para qualquer projeto de inclusão digital), o desafio maior da inclusão cidadã à cultura digital é fazer com que os indivíduos possam produzir conteúdos próprios e distribuí-los livremente mantendose senhor de seus dados pessoais, garantindo-se a privacidade e 0 anonimato.

Em outras palavras, processos de inclusão digital devem supor uma apropriação social e autoral das tecnologias digitais de rede. Isto é, que o sujeito empodere-se desses artefatos como autor, criador e produtor de conhecimento e de cultura, tendo como garantia as premissas de privacidade e de anonimato quando julgar necessário.

Nesse contexto, processos de inclusão digital pressupõem, para além do acesso aos artefatos tecnológicos da cultura digital, empoderamento, fluência, autoria e exercício da cidadania em rede. Neste sentido, inclusão digital é vista como

[...] um processo que fomenta apropriações tecnológicas nas quais os sujeitos são compreendidos como produtores ativos de conhecimento e de cultura, em uma dinâmica reticular que privilegia a vivência de 
características nucleares na sociedade contemporânea, como a interação, a autoria e a colaboração. Inclusão digital pressupõe o empoderamento por meio das tecnologias, a garantia à equidade social e à valorização da diversidade, suprindo necessidades individuais e coletivas, visando à transformação das próprias condições de existência e o exercício da cidadania na rede (MARCON, 2015, p. 99).

Esse conceito perpassa três eixos, que auxiliam a sua compreensão, sendo eles: 1) Apropriação/Fluência/Empoderamento Tecnológico; 2) Produção/Autoria individual/coletiva de conhecimento e de cultura e 3) Exercício da cidadania na rede.

O eixo 1 - Apropriação/Fluência/Empoderamento Tecnológico - diz respeito ao acesso, à apropriação, ao domínio e à fluência tecnológica, elementos necessários para reconhecer e transitar pela linguagem hipermidiática, condutora da cultura digital. É nesse eixo que dialogamos com os diferentes níveis de apropriação tecnológica e letramento digital, reconhecendo a necessidade de se assegurar a equidade de acesso, bem como oportunizar o empoderamento dos sujeitos por meio das tecnologias digitais de rede, reconhecendo seu potencial comunicacional, educativo e político (MARCON, 2015).

O eixo 2 - Produção/Autoria individual/coletiva de conhecimento e cultura compreende os sujeitos como autores e produtores ativos de conhecimento e de cultura. As TDR potencializam a vivência de processos comunicacionais interativos, autorais e colaborativos. Com a abertura dos polos de emissão, a cibercultura autoriza o sujeito a se expressar, interagir e participar. Supera-se a comunicação unidirecional e os limites temporais e espaciais, privilegia-se a interação todostodos. É nesse eixo que correlacionamos a inclusão digital com a apropriação crítica e criativa das tecnologias digitais de rede, na qual os sujeitos, além de consumidores, são autorizados a criar, produzir e compartilhar informações, conhecimentos e cultura (MARCON, 2015).

O eixo 3 - Exercício da cidadania na rede - refere-se à garantia de participação política dos sujeitos no ciberespaço e à valorização da diversidade social. Reconhecemos que a apropriação tecnológica pode acontecer de acordo com a realidade e interesses de cada sujeito, isso é, cada um apropria-se das tecnologias de acordo com as suas necessidades individuais, coletivas ou 
comunitárias. Nesse eixo, fazemos uma interlocução com propostas que objetivam o reconhecimento das TDR como propulsoras de transformação das próprias condições de existência e do exercício da cidadania na rede (MARCON, 2015).

Com esses três eixos é possível reconhecer "[...] o potencial das tecnologias digitais de rede para a concretização de processos educativos autorais, criativos e colaborativos" (MARCON, 2015, p. 100), além da perspectiva política que envolve a apropriação das tecnologias digitais. A partir dessas três dimensões e do reconhecimento de que processos de inclusão digital superam unicamente o acesso às tecnologias, precisamos pensar, então, o que significa ser um excluído digital em contexto de isolamento social, tema sobre o qual discorreremos no item a seguir.

\section{0 que significa ser um excluído digital em um contexto de isolamento social?}

Bonilla e Oliveira (2011, p. 24) trazem à discussão a importância de pensar sobre a desigualdade de acesso às tecnologias digitais de rede, disparidades nomeadas genericamente como "digital divide, gap digital, apartheid digital, infoexclusão, ou exclusão digital'. Ao referirem-se à exclusão digital, os autores evocam as palavras de Sérgio Amadeu da Silveira, que acredita que a "exclusão digital impede que se reduza a exclusão social, uma vez que as principais atividades econômicas, governamentais e boa parte da produção cultural da sociedade vão migrando para a rede" (apud BONILLA; OLIVEIRA, 2011, p. 30), ou seja, a exclusão desses movimentos ocasiona a desigualdade de acesso à produção cultural da sociedade, reforçando o conceito proposto por Lemos (2011) anteriormente.

No rompimento dessa esfera de alienação e de exclusão, "a grande dificuldade se apresenta, na maioria dos casos, entre aqueles que se constituíram numa cultura estritamente analógica, alfabetizados ou não, por não compreenderem, pelo menos não de imediato, a lógica digital" (BONILLA, OLIVEIRA, 2011, p. 39). De acordo com Jenkins (2009), estamos vivenciando um momento de transição e convergência, em que um paradigma midiático está expirando e outro está surgindo. Existe, hoje, uma coexistência entre o paradigma dos meios de comunicação de massa e o paradigma comunicacional das redes. 


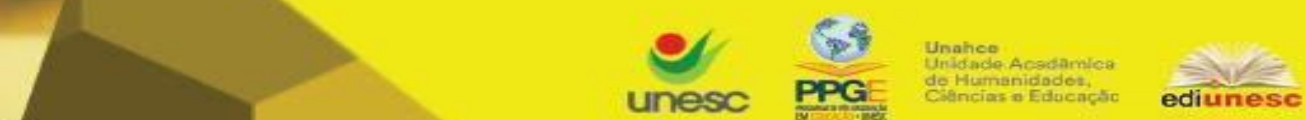

Criar Educação, Criciúma, v. 9, ㄲo2, Edição Especial 2020.- PPGE - UNESC - ISSN 2317-2452

Os meios de comunicação de massa suportam processos de comunicação nos quais não há trocas nem interação entre os usuários e emissores das mensagens, e, uma vez que possuem grande alcance na audiência, procuram perpetuar a condição de consumidores dos sujeitos, seja de bens privados ou de concepções, como aborda Canclini (2001, p. 37):

\begin{abstract}
Homens e mulheres percebem que muitas das perguntas próprias dos cidadãos - a que lugar eu pertenço e que direitos isso me dá, como posso me informar, quem representa meus interesses - recebem sua resposta mais através do consumo privado de bens e dos meios de comunicação de massa do que nas regras abstratas da democracia ou pela participação coletiva em espaços públicos.
\end{abstract}

O que se percebe é que as práticas dos meios de comunicação de massa, muitas vezes, circunscrevem a existência do indivíduo à condição de consumidor. O cidadão começa a exercer seu papel e a demonstrar sua participação, na sociedade civil, através dos valores simbólicos que carrega consigo - fruto das relações sociais de que faz parte - ou através de signos de prestígio que possui, como bens materiais que categorizam a que classe pertence dentro da sociedade.

Em contrapartida, com as tecnologias de rede, o sujeito tem o potencial de participar, compartilhar, interagir, pois da lógica de redes emerge um processo diferenciado daquele apresentado até o momento. Esse novo contexto potencializa espaços comunicativos até então inexistentes, nos quais ampliam-se as fontes de informação e rompe-se gradativamente com o poder antes exercido somente pelos meios de comunicação de massa. Sobre isso, Castells (1999, p. 298-299) expõe que "[...] a explosão das telecomunicações e o desenvolvimento dos sistemas de transmissão a cabo viabilizaram o surgimento de um poder de transmissão e difusão de informações sem precedentes [...]". Estabeleceu-se sincronia entre tempo e espaço, permitindo uma articulação entre diferentes pontos do mundo, de maneira imediata e instantânea.

Essas são características de uma sociedade que possui sua vivência ajustada pelas tecnologias digitais e que foi denominada por Castells (2005, p. 87) como "sociedade em rede". O autor considera que a sociedade em rede é aquela "cuja estrutura social foi construída em torno de redes de informação a partir da 
tecnologia de informação microeletrônica estruturada na internet" (CASTELLS, 2005, p. 87).

Entretanto, entendemos que a utilização de tecnologias digitais de rede em situações do cotidiano não implica, necessariamente, em vivências de processos de inclusão digital, tal como compreendemos o referido conceito. Para além do acesso às tecnologias, os sujeitos podem estar vivenciando processos de exclusão digital ou de subutilização das tecnologias em uma perspectiva de consumo, tendo como foco as mídias sociais e os contextos de desinformação e fake news.

Para Primo (2010, p. 09) cada vez é mais visível o "[...] borramento da fronteira entre produção e consumo". Na concepção do autor, por meio da rede foram acentuadas a liberdade de expressão e da circulação de informações, tendo em vista a simplificação das ferramentas de produção e a popularização de redes sociais. Isso ocasionou um "[...] empoderamento das pessoas desvinculadas de instituições midiáticas" (PRIMO, 2010, p. 09).

Ao mesmo tempo em que temos uma amplitude de possibilidades de emissão de mensagens e de circulação de informações, passamos a conviver em contextos de desinformação, principalmente em função da produção de fake news. Allcott e Gentzkow (2017) definem este fenômeno como "artigos noticiosos que são intencionalmente falsos e aptos a serem verificados como tal, e que podem enganar os leitores" (apud DELMAZO; VALENTE, 2018, s/p.).

Para Ellison e Boyd, "esses conteúdos encontram um terreno fértil nos sites de redes sociais" (apud DELMAZO; VALENTE, 2018, s/p.), porque, "os utilizadores de dados tendem a confiar em opiniões formadas e moldadas por grupos influentes" (BALDACCI; BUONO; GRASS apud DELMAZO; VALENTE, 2018, s/p.). Temos, atualmente, uma diversificação de perfis e canais de influencers digitais, que possuem milhões de seguidores e assinantes de seus conteúdos. Os autores ainda apontam que "a ampliação do consumo de notícias por sites de redes sociais também fomenta um novo tipo de concorrência com os media tradicionais. As fake news se assentam, também, na crise de confiança dos leitores nos veículos tradicionais" (DELMAZO; VALENTE, 2018, s/p.). 
Essa crise de confiança entre os meios de comunicação de massa e a produção ilimitada de conteúdo em mídias sociais contextualiza a chamada era da pós-verdade. O termo foi eleito pela Universidade de Oxford em 2016 como "a palavra do ano", e de acordo com o Dicionário Oxford (2016) está "relacionado a uma situação em que as pessoas têm maior probabilidade de aceitar um argumento com base em suas emoções e crenças, em vez de com base em fatos" (tradução livre).

A pesquisadora Alexis Wichowski, no vídeo "Pós-verdade na era da informação", diz que a pós-verdade consiste na "relativização da verdade", e que as pessoas ignoram os fatos por não quererem encarar a verdade, procurando a verdade que é confortável para si mesmo. Para ela, é um termo conveniente para a política e negócios, e que "seria uma época de aceitação de mentiras" (WICHOWSKI, 2017).

Uma forma de exclusão digital, neste contexto, perpassa por essa utilização acrítica e centralizada da informação, em uma perspectiva de consumo nas mídias sociais. Processos de inclusão digital tratam da apropriação crítica das tecnologias, e igualmente devem compreender a leitura crítica da mídia e o confrontamento da desinformação com a informação.

Por fim, nesse contexto em que, de forma crítica, é possível pressupor movimentos coletivos e descentralizados de produção de conteúdo, a necessidade de assumir-se como sujeito crítico potencializa o exercício da cidadania na rede e invalida o modelo de reprodução e consumo. Bonilla e Pretto (2011) acreditam que a rede possui características hipertextuais e interativas, e que haveria uma evolução nos processos educativos se essas características fossem exploradas em sua essência. Esse e outros potenciais pedagógicos que as tecnologias digitais de rede possuem para os processos educativos são questões sobre as quais dialogamos no item a seguir.

\section{Qual o potencial pedagógico das tecnologias digitais de rede para os processos educativos?}




\section{CRIAR EDUCAÇÃO}

Revista do Programa de Pós-Graduação em Educação - UNESC

\section{(1)
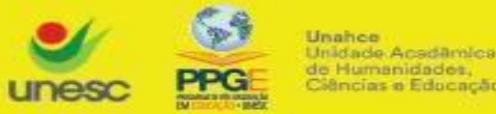 \\ Co Aumanidiodos, ediunesc}

Criar Educação, Criciúma, v. 9, №2, Edição Especial 2020.- PPGE - UNESC - ISSN 2317-2452

A partir dessa nova reconfiguração social, comunicacional e educacional, instituída a partir da chegada das TDR, novas situações de aprendizagem foram tecidas. Para Pozo, as mudanças radicais na cultura da aprendizagem "estão ligadas historicamente ao desenvolvimento de novas tecnologias na conservação e na difusão da informação" (POZO, 2002, p.34), que proporcionam experiências de aprendizagem baseadas em processos coletivos, trocas e reflexões.

Nos processos formativos hodiernos, há que se pensar em ambiências formativas que, de acordo com Santos (2015, p. 40),

[...] são as situações de aprendizagem cocriadas nos espaçostempos híbridos em que se articulam os ambientes físicos e digitais (sala de aula presencial, ambientes virtuais de aprendizagem e redes sociais). Uma ambiência formativa é o complexo enredamento onde se dinamizam diversas possibilidades de produção intelectual, de invenção, de constituição de rastros onde um coletivo assume, explicita e reinventa seu processo de formação.

Acreditamos que a utilização das tecnologias precisa estimular o envolvimento, a criatividade, a curiosidade, elementos que possibilitam ao sujeito a busca e a construção do próprio conhecimento e que precisam ser consideradas nos desenhos didáticos em processos educativos online. Santos, Ribeiro e Carvalho (2020, s/p.) entendem, por ambiência

o espaço organizacional vivo, estético, político, formativo e híbrido (virtual/presencial), que envolve e torna a sala de aula mais receptível/flexível para os estudantes, tanto no desenvolvimento de atividades, quanto nas situações de aprendizagem e na constituição de novos arranjos comunicacionais, que viabiliza o entrelaçamento de cocriações formativas entre professor-estudantes e estudantesestudantes.

A pandemia Covid-19 que acomete o mundo neste momento nos permite pensar que processos educativos híbridos tendem a tornar-se uma realidade cada vez mais concreta em um futuro próximo. Essas ambiências híbridas são classificadas em três pilares, que podem ser compreendidos na figura abaixo: 


\section{CRIAR EDUCAÇÃOO}

Revista do Programa de Pós-Graduação em Educação - UNESC

\section{X $2 \ddot{2}=$ \\ ediunesc}

Criar Educação, Criciúma, v. 9, n²2, Edição Especial 2020.- PPGE - UNESC - ISSN 2317-2452

\section{Imagem 04 - Pilares da ambiência híbrida}

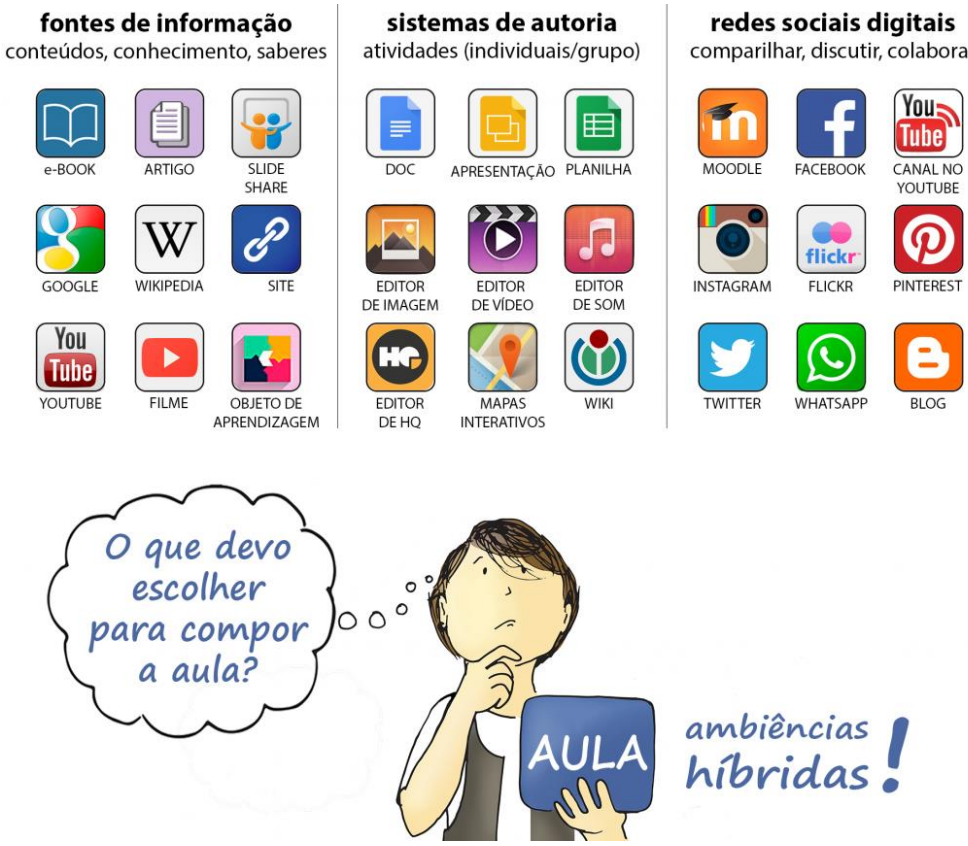

Fonte: CARVALHO, 2015.

De acordo com os registros de Santos, Ribeiro e Carvalho (2020), essas ambiências híbridas foram organizadas em fontes de informações, "para situar a temática, prática e concepção que faz parte da aula ou atividade"; em sistemas de autoria, "para a manifestação de autorias nas ações de aprendizagem individual/dupla/grupo"; e em redes sociais digitais, "para compartilhar, discutir e tecer o conhecimento mais aberto e informal, proporcionando a tessitura dos atos de currículo para além dos espaçostempos institucionais" (SANTOS; RIBEIRO; CARVALHO, 2020, s/p.). 


\section{CRIAR EDUCAÇÃO}

Revista do Programa de Pós-Graduação em Educação - UNESC

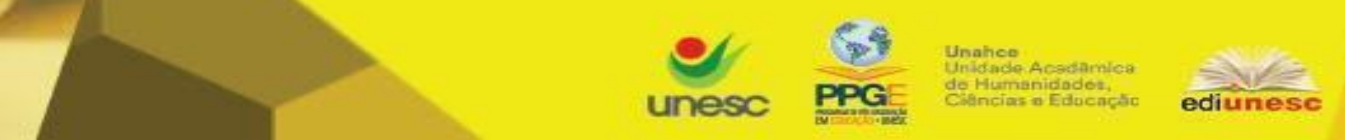

Criar Educação, Criciúma, v. 9, n²2, Edição Especial 2020.- PPGE - UNESC - ISSN 2317-2452

O planejamento intencional de um processo educativo combinando essas ambiências pode oportunizar a vivência de processos de inclusão digital, garantindo a fluência tecnológica na linguagem hipermidiática, a apropriação autoral e coletiva e o exercício da cidadania na rede, de forma a transformar a própria realidade. Importante considerar que esse planejamento terá implicações a partir da inclusão e da exclusão digital na formação dos educadores, considerando os desdobramentos que ocorrem nas práticas pedagógicas, questões que serão pensadas a seguir.

\section{Quais as implicações da inclusão e da exclusão digital na formação de educadores e seus desdobramentos nas práticas pedagógicas?}

Pensar nos processos educativos por um viés comunicacional implica considerar a apropriação das tecnologias digitais de rede na formação inicial de educadores. Se precisamos de docentes qualificados e preparados para atuar em um contexto que é plástico, flexível e que se molda com facilidade às inúmeras transformações sociais, precisamos preparar esses docentes para vivenciarem e imergirem nessa cultura que se apresenta.

Pesquisas sobre a integração de tecnologias digitais na formação inicial de professores nos fazem questionar se realmente essa discussão vem sendo contemplada nos currículos dos cursos de licenciatura. Os dados da pesquisa TIC Educação (2018) nos mostram que $43 \%$ dos professores entrevistados haviam cursado uma disciplina durante a graduação sobre o uso de tecnologias na aprendizagem: 


\section{CRIAR EDUCAÇÃO}

Revista do Programa de Pós-Graduação em Educação - UNESC

\section{Unesc PPGE \\ ediunesc}

Criar Educação, Criciúma, v. 9, n²2, Edição Especial 2020.- PPGE - UNESC - ISSN 2317-2452

PROFESSORES, FORMAÇÃO INICIAL

Total de professores de escolas urbanas (\%)

Professores que cursaram uma disciplina durante a graduação sobre o uso de tecnologias na aprendizagem

(2014-2018)

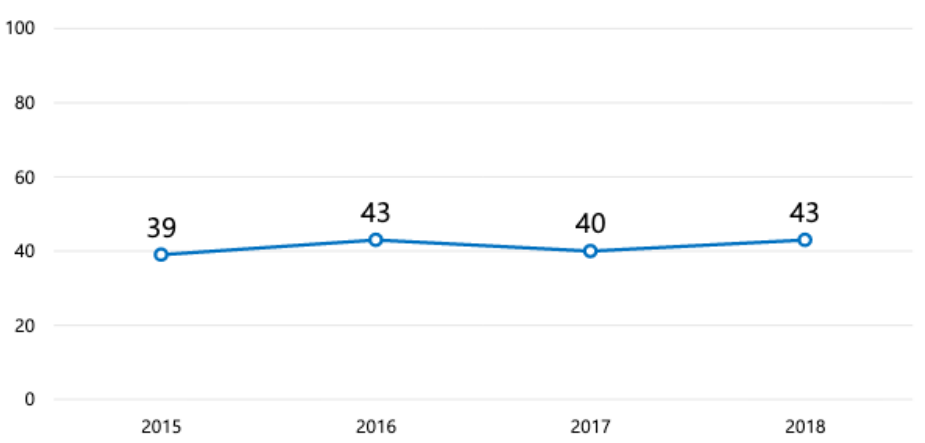

Por disciplina que leciona (2018)

\begin{tabular}{lc}
\hline Língua portuguesa & $\mathbf{3 2}$ \\
\hline $\begin{array}{l}\text { Múltiplas disciplinas } \\
\text { (anos iniciais do Ensino }\end{array}$ & $\mathbf{4 0}$ \\
$\begin{array}{l}\text { Fundamental) } \\
\text { Matemática }\end{array}$ & $\mathbf{5 8}$
\end{tabular}

Fonte: TIC EDUCAÇÃO 2018 (Cetic.br, 2018)

É possível perceber, também, que não há uma curva de crescimento sobre a formação inicial com relação aos anos anteriores, mantendo-se em uma média de cerca de $41 \%$ referente ao período 2015-2018. Outros dados interessantes estão disponibilizados no gráfico abaixo, sobre a participação dos professores em cursos, utilização das tecnologias em sala de aula e realização de projetos sobre tecnologias em atividades de ensino-aprendizagem:

Imagem 06 - Formação inicial: cursos, utilização de tecnologias em sala de aula e projetos 


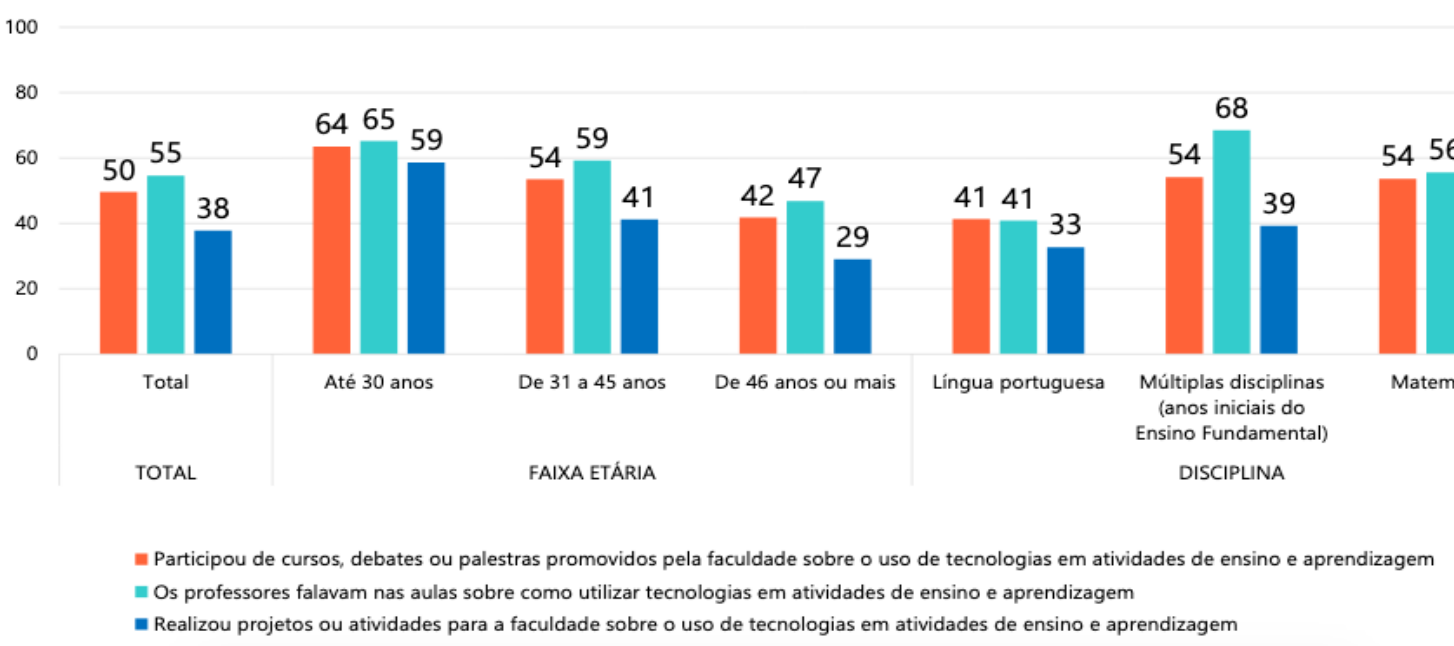

Fonte: TIC EDUCAÇÃO 2018 (Cetic.br, 2018)

Conforme podemos observar, $50 \%$ dos professores entrevistados participaram de cursos, debates ou palestras promovidos pela faculdade sobre 0 uso de tecnologias em atividades de ensino-aprendizagem. 55\% dos respondentes registraram que em seus cursos de formação inicial seus professores dos falavam nas aulas sobre como utilizar as tecnologias em atividades de ensinoaprendizagem, enquanto apenas 38\% realizaram projetos ou atividades sobre o uso de tecnologias em atividades de ensino e aprendizagem. Esses mesmos indicadores são apresentados por faixa etária e disciplinas, sendo que os maiores índices referem-se a professores cuja idade é até 30 anos, que trabalham com múltiplas disciplinas nos anos iniciais do ensino fundamental.

Outro dado apresentado na pesquisa é sobre o uso de telefone celular com os alunos: 


\section{CRIAR EDUCAÇÃO}

Revista do Programa de Pós-Graduação em Educação - UNESC

\section{unesc PPGE}

Criar Educação, Criciúma, v. 9, n²2, Edição Especial 2020.- PPGE - UNESC - ISSN 2317-2452

Imagem 07 - Uso de telefone celular com os alunos

\section{PROFESSORES, USO DO TELEFONE CELULAR EM ATIVIDADES COM OS ALUNOS}

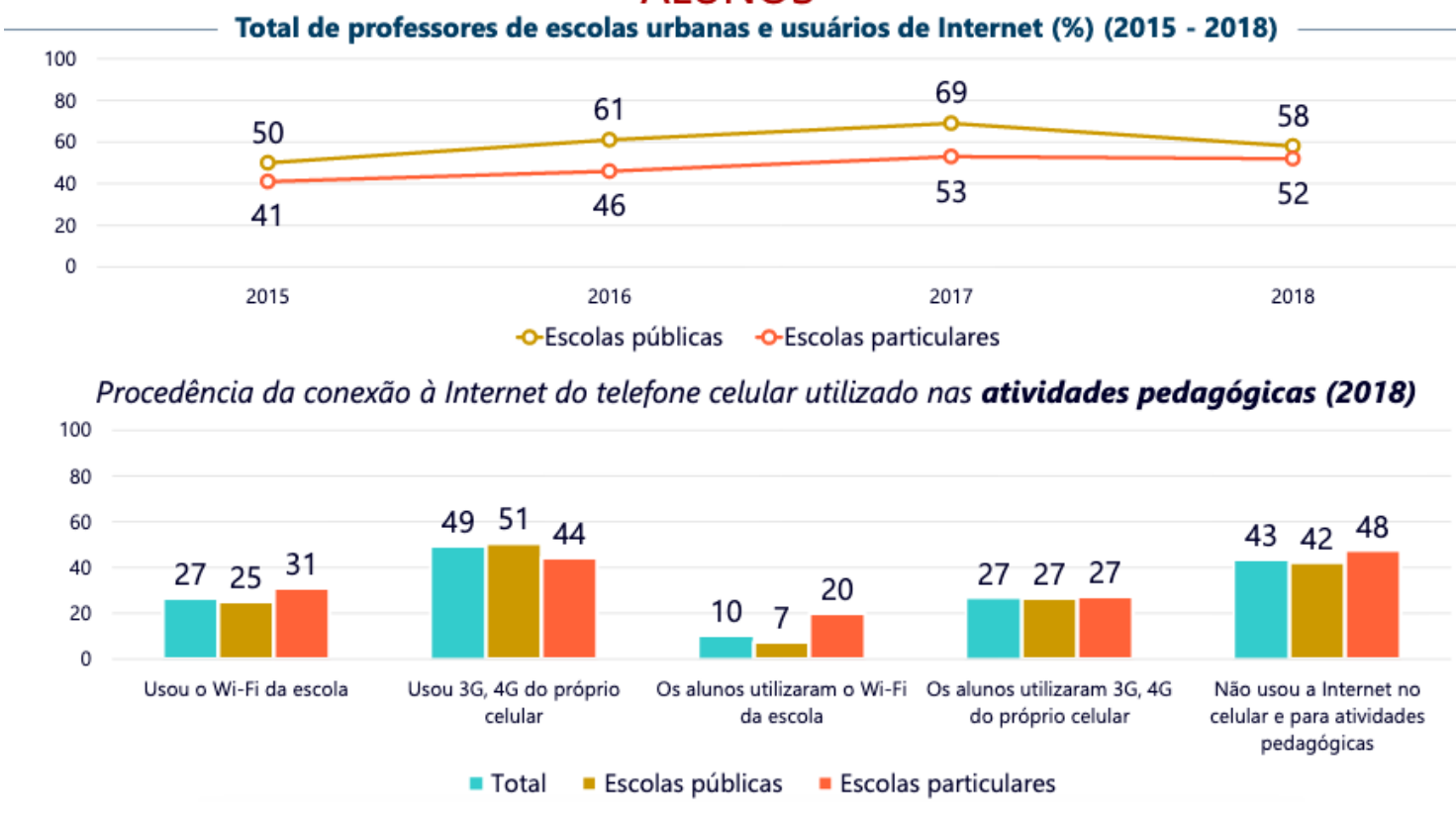

Fonte: TIC EDUCAÇÃO 2018 (Cetic.br, 2018)

É possível identificar que $58 \%$ dos professores das escolas públicas e $52 \%$ dos professores das escolas particulares utilizaram telefone celular em atividades com os alunos. Em comparação com os anos anteriores, houve uma curva de crescimento nos anos de 2015, 2016 e 2017, mas um decréscimo em ambos os casos no ano de 2018. Outra observação importante é que apenas $25 \%$ dos professores das escolas públicas e $31 \%$ das escolas privadas utilizaram o wi-fi da escola para realização de atividades pedagógicas com o celular. Essa utilização, referente aos alunos, diminui para $7 \%$ e $10 \%$, respectivamente, sendo que $42 \%$ (escolas públicas) e $48 \%$ (escolas particulares) não utilizaram a internet no celular para atividades pedagógicas.

Todos esses dados reforçam que a formação inicial de educadores precisa ser um lócus de aprendizagem que oportuniza aos licenciandos o desenvolvimento de saberes e competências intrínsecos ao momento contemporâneo. Entendemos que a formação inicial de professores não pode e não tem mais como deixar as tecnologias afastadas do currículo, como se fossem recursos extraclasse. $O$ 


\title{
(1)
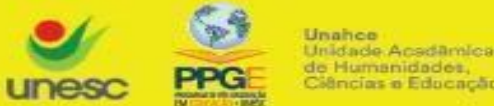

Criar Educação, Criciúma, v. 9, №2, Edição Especial 2020.- PPGE - UNESC - ISSN 2317-2452

professor precisa estar preparado para trabalhar na presença das tecnologias e, principalmente, com as tecnologias. A percepção de Karsenti (2011, p. 182) é equivalente às nossas colocações:

\begin{abstract}
Postulamos assim que as novas tecnologias não podem mais ser consideradas, como eram até agora, como aperfeiçoamentos extrínsecos e instrumentais, cursos destacados da prática profissional diária. Pelo contrário, afirmamos que elas são capazes de trazer uma mudança profunda à formação no meio prático, assim como no futuro perfil de prática dos docentes em formação.
\end{abstract}

Os autores Tardif e Lessard (2011, p. 20-21) refletem sobre o posicionamento de Karsenti:

\begin{abstract}
[...] a integração das TIC exige, por parte dos futuros professores, uma modificação da relação com o saber e acarreta uma maior inflexão no plano das práticas pedagógicas. Essa ideia o leva a criticar visões estritamente instrumentalistas das relações entre as TIC e a formação dos professores, em que as TIC são consideradas como ferramentas técnicas e supletivas, que deveriam ser objeto de uma aprendizagem especializada por parte dos futuros professores. Ao contrário dessas visões, Karsenti defende uma integração sistemática e vivida das TIC em todos os cursos de formação para o ensino, pois, segundo ele, a aprendizagem das TIC passa pela aquisição de competências transversais que englobam a totalidade da formação. Nesse percurso, ele situa o futuro professor no centro da aprendizagem das TIC, levando em conta, ao mesmo tempo, o contexto que lhe permite construir a sua própria competência.
\end{abstract}

Assim como Karsenti (2011), compreendemos que essa integração das tecnologias precisa ser sistemática e experienciada na formação desses docentes. Para poder fomentar esses aspectos em sala de aula, o professor precisa estar preparado, e, nesse sentido, a formação inicial assume papel importante na trajetória pedagógica desses estudantes, pois assim como Bélanger (2005, p. 193), acreditamos que "[...] quanto mais as pessoas se formam, mais tendem a prosseguir na formação. Cria-se então uma espiral: a participação na educação dos adultos é fortemente influenciada pela qualidade e pela intensidade da formação inicial". Isto é, a qualidade dos cursos de licenciatura desempenha papel fundamental na constituição de docentes que continuarão se aperfeiçoando mesmo após a conclusão do seu curso, característica que deve ser preconizada na sociedade contemporânea. 


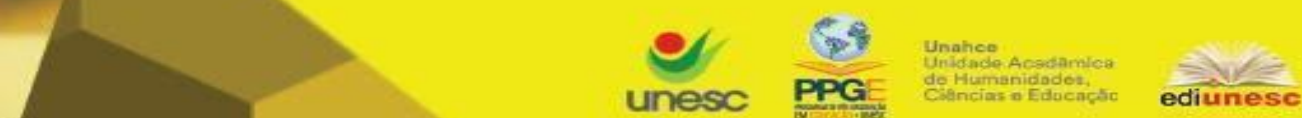

Criar Educação, Criciúma, v. 9, ํํ2, Edição Especial 2020.- PPGE - UNESC - ISSN 2317-2452

As tecnologias digitais de rede e a web 2.0 potencializam essa dinâmica intrínseca aos movimentos da rede, como a interatividade, a coletividade e a cooperação, e é nesse sentido que julgamos que além de fomentar processos de ensino-aprendizagem considerando o contexto social contemporâneo, é preciso reconhecer o papel desempenhado pelas tecnologias digitais de rede nesse cenário, bem como o potencial pedagógico das mesmas.

Lepeltak e Verlinden (2005, p.216) destacam que

\begin{abstract}
Diversas pesquisas mostraram que os professores desempenhavam um papel decisivo na aplicação de novas tecnologias. Esse papel é determinado, em larga medida, pela organização da escola, pela concepção que os professores têm do ensino e dos métodos de ensino, por seu conhecimento da tecnologia da informação e de suas aplicações pedagógicas, pela disponibilidade do hardware de informática e de softwares, pelas vantagens que a aplicação das novas tecnologias permitiu obter.
\end{abstract}

Para conseguir lidar com a integração das tecnologias digitais de rede nas práticas pedagógicas e trabalhar na perspectiva da inclusão digital com os estudantes, acreditamos que primeiramente o professor deve ter fluência tecnológica. Entretanto, por mais que seja atribuída ao professor a maior responsabilidade na promoção de processos de inclusão digital dos estudantes, é preciso considerar outras questões, que se referem principalmente ao posicionamento da gestão escolar e à disponibilização dos recursos tecnológicos nas escolas. Lepeltak e Verlinden (2005, p. 218) ressaltam esses desafios impostos à docência:

Os professores podem ver nisso um enorme desafio ou, ao contrário, uma
nova fonte de grandes frustrações, sobretudo quando lhe pedem que faça
coisas impossíveis na conjuntura atual (conhecimento insuficiente das
tecnologias da informação, organização escolar rígida, falta de
equipamento, integração insuficiente dessas tecnologias no programa de
estudos, poucas perspectivas de progresso ou de especialização, etc.). Em
outras palavras, toda pressão resultante da inadequação entre a demanda
da sociedade e dos alunos e a oferta de ensino recai sobre o professor.

Essas questões estão bem atuais neste contexto de pandemia da Covid-19, onde acompanhamos a aceleração da formação técnica do professor (mas não 
pedagógica), para trabalhar com ensino mediado pelas tecnologias na educação básica ou superior. Acreditamos que o professor desempenha papel fundamental, sim, entretanto não pode ser considerado o único responsável pelas inadequações sobre as quais já arguimos. Em nossa opinião, o docente é o agente central, porém trata-se de um processo muito complexo que precisa ser considerado em sua totalidade, não fragmentado e descontextualizado.

Neste sentido, entendemos que as implicações da inclusão e da exclusão digital na formação de educadores possuem desdobramentos impactantes nas práticas pedagógicas, principalmente quando consideramos que nem todos os educadores/as participaram de processos de inclusão digital na perspectiva aqui apontada, a partir da realidade concreta apresentada nas pesquisas. Isso ocasionará, como desdobramento em suas práticas, a ausência de relações das características interativas, de convergência e autoria colaborativa das tecnologias digitais de rede com referenciais teóricos do campo pedagógico. Ainda, podemos destacar a ausência da objetivação pedagógica das TDR, no que diz respeito principalmente a elaboração de forma crítica e criativa dos planejamentos pedagógicos que situem as TDR nos processos de ensino-aprendizagem.

A exclusão digital dos docentes pode ocasionar, portanto, a ausência do reconhecimento do potencial pedagógico das TDR, subutilizando as tecnologias como meios de transmissão de conhecimento aos educandos. Freire (1988, p. 69) já nos ensinava que "a educação é comunicação, é diálogo, na medida em que não é a transferência de saber, mas um encontro de sujeitos interlocutores que buscam a significação dos significados". De acordo com Lima (2004, p.55, grifo do autor), "contrapondo a comunicação à transmissão, Freire argumenta que comunicação é a 'co-participação de Sujeitos no ato de conhecer' e que a extensão implica transmissão, transferência, invasão".

Neste sentido, há que suplantar a pedagogia da transmissão uma vez que conhecer supera a transferência ou a transmissão. É preciso pensar em uma pedagogia interativa, na qual os processos educativos se estabelecem por meio da comunicação e do diálogo, que se tornam elementos essenciais para que os 
processos de aprendizagem se efetivem em uma perspectiva de participação e não de consumo.

\section{Considerações finais: Que educação estamos praticando e para quem, neste contexto de pandemia?}

Neste contexto de isolamento social ocasionado pela pandemia Covid-19, escolas e universidades tiveram que fazer uso das tecnologias digitais de rede para mediação e continuidade dos processos de ensino-aprendizagem que não puderam mais ser realizados presencialmente. Entretanto, os dados sobre acesso aos computadores e à internet nos domicílios brasileiros apresentados na Pesquisa TIC Domicílios (CGI.BR, 2019) são preocupantes e demonstram uma disparidade de acesso aos recursos tecnológicos.

Observamos que 99\% da população que fez uso da internet no ano de 2019 utilizou por meio de telefone celular, e que há uma diferença profunda e marcante de acesso de acordo com a classe social. A pergunta "que educação estamos fazendo e para quem?", neste trabalho, busca problematizar justamente essa disparidade, considerando as condições objetivas de acesso às tecnologias para dar seguimento aos estudos.

Contudo, para além do acesso, as pessoas podem estar subutilizando as tecnologias digitais, e, neste sentido, a discussão realizada neste texto igualmente passou pela necessidade de os sujeitos se apropriarem das tecnologias em uma perspectiva também de autoria, não somente de consumo.

Para que isso aconteça, há que se fomentar práticas educativas que considerem a inclusão digital e o potencial pedagógico das tecnologias, e neste sentido a formação inicial dos educadores possui importante desdobramento em suas práticas pedagógicas. A formação inicial precisa estar articulada com o contexto comunicacional e tecnológico contemporâneo e não pode mais ser dissociada de processos de apropriação de tecnologias. Em contextos como estes que estamos vivendo, essa desarticulação pode ocasionar processos de ensinoaprendizagem com ausência da objetivação pedagógica e ausência do 


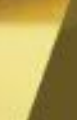
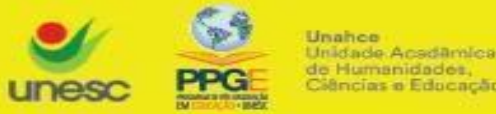 \\ ediunesc}

Criar Educação, Criciúma, v. 9, №2, Edição Especial 2020.- PPGE - UNESC - ISSN 2317-2452

reconhecimento do potencial pedagógico das TDR, subutilizando as tecnologias como meios de transmissão de conhecimento aos educandos.

Por fim, conforme vimos, muitos são os desafios em contextos de pandemia, mas a compreensão do que significa ser incluído e excluído digital é essencial e perpassa esse momento social em que vivemos, bem como as discussões no âmbito da educação que se desdobram atualmente em função da pandemia Covid19.

\section{Referências}

BÉLANGER, Paul. Sociedades Educacionais em Gestação. In: DELORS, Jacques. Educação para o século XXI. Porto Alegre: Artmed, 2005, p. 192-205.

BONILLA, Maria Helena; OLIVEIRA, Paulo Cezar Sousa de. Inclusão Digital: Ambiguidades em curso. In: BONILLA, Maria Helena; PRETTO, Nelson de Luca. Inclusão Digital: polêmica contemporânea. v. 2. Salvador: EDUFBA, 2011, p. 15-21.

BONILLA, Maria Helena; PRETTO, Nelson de Luca. Apresentação. In: BONILLA, Maria Helena; PRETTO, Nelson de Luca. Inclusão Digital: polêmica contemporânea. v. 2. Salvador: EDUFBA, 2011.

BONILLA, Maria Helena. Educação e Inclusão Digital. GEC: Grupo de Pesquisa em Educação, Comunicação e Tecnologias, 2004. Disponível em: <http://www.twiki.ufba.br/twiki/bin/view/GEC/MariaHelenaBonilla>. Acesso em 10 jun. 2020.

CANCLINI, Nestor García. Consumidores e Cidadãos: Conflitos Multiculturais da Globalização. Rio de Janeiro: Editora UFRJ, 2001.

CARVALHO, Felipe da Silva Ponte. Atos do Currículo na Educação Online. Rio de Janeiro, 2015. Disponível em: . Dissertação (Mestrado em Educação) ProPed/Uerj. Disponível em: <http://www.proped.pro.br/teses/teses_pdf/2013_21195-ME.pdf>. Acesso em: jun. 2020.

CASTELLS, Manuel. A era da Informação: Economia, Sociedade e Cultura - O Poder da Identidade. Vol.2. 3ํㅡㄹ ed. São Paulo: Paz e Terra, 1999.

CASTELLS, Manuel. A internet e Sociedade em Rede. In: MORAES, Dênis de (org). Por uma outra comunicação - Mídia, mundialização cultural e poder. 3 ed. Rio de Janeiro: Record, 2005, p.225-231. 
CETIC.Br, Centro Regional de Estudos para o Desenvolvimento da Sociedade da Informação. Pesquisa TIC Educação 2018 (Cetic.br, 2018). Disponível em: <https://cetic.br/media/analises/tic_educacao_2018_coletiva_de_imprensa.pdf>. Acesso em: 12 jun. 2020.

CGI.br, Comitê Gestor da Internet no Brasil. Pesquisa TIC Domicílios 2019.

Disponível em: <https://www.cetic.br/media/analises/tic_domicilios_2019_coletiva _imprensa.pdf>. Acesso em: 12 jun. 2020.

DELMAZO, Caroline; VALENTE; Jonas C...; Fake news nas redes sociais online: propagação e reações à desinformação em busca de cliques. Media \& Jornalismo. Vol.18, №. 32. Lisboa, Abr. 2018. Acesso em: <http://www.scielo.mec.pt/scielo.php?script=sci_arttext\&pid=S218354622018000100012>. Acesso em: 10 jun. 2020.

DICIONÁRIO OXFORD. Post-truth. (2016). Disponível em: <https://dictionary. cambridge.org/pt/dicionario/ingles/post-truth>. Acesso em: 10 jun. 2020.

FREIRE, Paulo. Comunicação ou Extensão? 10 ed. Rio de Janeiro: Paz e Terra, 1988.

JENKINS, Henry. Cultura da Convergência. Trad. Susana Alexandria. 2 ed. São Paulo: Aleph, 2009.

KARSENTI, Thierry. Impacto das TIC (Tecnologias de Informação e Comunicação) sobre a atitude, a motivação e a mudança nas práticas pedagógicas dos futuros professores. In: TARDIF, Maurice; LESSARD, Claude. O ofício de professor: história, perspectivas e desafios internacionais. 4 ed. Petrópolis, RJ: Vozes, 2011, pp. 181-199.

LEMOS, André. Prólogo. In: BONILLA, Maria Helena; PRETTO, Nelson de Luca. Inclusão Digital: polêmica contemporânea. v. 2. Salvador: EDUFBA, 2011, p. 1521.

LEPELTAK, Jan; VERLINDEN, Claire. Ensinar na Era da informação: Problemas e Novas Perspectivas. In: DELORS, Jacques. Educação para o século XXI. Porto Alegre: Artmed, 2005, p. 206-221.

LIMA, Venício A. de. Mídia: Teoria e Política. $2^{\text {a }}$ ed. São Paulo: Editora Fundação Perseu Abramo, 2004.

MARCON, Karina. A inclusão digital de educadores a distância: Estudo multicaso nas Universidades Abertas do Brasil e de Portugal. 2015. Tese (Doutorado em Educação). Programa de Pós-Graduação em Educação, Universidade Federal do Rio Grande do Sul, 2015. 


\section{CRIAR EDUCAÇÃO}

Revista do Programa de Pós-Graduação em Educação - UNESC

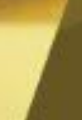
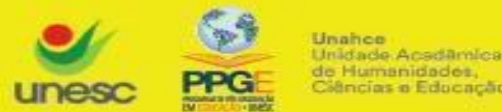 \\ Cienciasnidodos, \\ ediunesc}

Criar Educação, Criciúma, v. 9, ㄲo2, Edição Especial 2020.- PPGE - UNESC - ISSN 2317-2452

MARCON, Karina. Processos Educativos e Comunicacionais na Cibercultura: Explorando Ações de Inclusão Digital. 2008. Dissertação (Mestrado em Educação). Programa de Pós-Graduação em Educação, Universidade de Passo Fundo. Passo Fundo: 2008.

POZO, Juan Ignacio. Aprendizes e Mestres: A nova cultura da aprendizagem. Porto Alegre: Artmed Editora, 2002.

PRIMO, Alex. Crítica da cultura da convergência: participação ou cooptação. In: DUARTE, Elizabeth Bastos; CASTRO, Maria Lília Dias de (Orgs.). Convergências

Midiáticas: produção ficcional - RBS TV. Porto Alegre: Sulina, 2010, p. 21-32.

SANTOS, Rosemary; RIBEIRO, Mayra Rodrigues Fernandes; CARVALHO, Felipe da Silva Ponte de. Educação Online: aprenderensinar em rede. Informática na Educação: Série de livros-texto da CEIE/SBC. Disponível em: $<$ https://informaticanaeducacao.uniriotec.br/2017/10/25/educacao-onlineaprenderensinar-em-rede/>. Acesso em: jun. 2020.

SANTOS, Rosemary. Formação de Formadores e Educação Superior na cibercultura: itinerâncias de Grupos de Pesquisa no Facebook. 2015. 183 f. Tese de Doutorado em Educação - Faculdade de Educação, Universidade do Estado do Rio de Janeiro, Rio de Janeiro, 2015.

TARDIF, Maurice; LESSARD, Claude. Introdução. In: TARDIF, Maurice; LESSARD, Claude. 0 ofício de professor: história, perspectivas e desafios internacionais. 4 ed. Petrópolis, RJ: Vozes, 2011, pp 7-22.

WICHOWSKI, Alexis. Pós-verdade na era da informação (vídeo). 2017. Disponível em: <https://www.youtube.com/watch?v=ImDegclAX70\&t=371s>. Acesso em: 10 jun. 2020. 